CLINICAL STUDY

\title{
Liquid meal composition, postprandial satiety hormones, and perceived appetite and satiety in obese women during acute caloric restriction
}

Timothy D Heden, Ying Liu, Lauren Sims, Monica L Kearney, Adam T Whaley-Connell ${ }^{1,2}$, Anand Chockalingam ${ }^{3}$, Kevin C Dellsperger ${ }^{3,4}$, Timothy J Fairchild ${ }^{5}$ and Jill A Kanaley

Department of Nutrition and Exercise Physiology, University of Missouri, 217 Gwynn Hall, Columbia, Missouri 65211, USA, ${ }^{1}$ Harry S. Truman VA Medical Center, Columbia, Missouri, USA, ${ }^{2}$ Division of Nephrology, Department of Internal Medicine, University of Missouri, Columbia, Missouri, USA, ${ }^{3}$ Division of Cardiovascular Medicine, Department of Internal Medicine, University of Missouri, Columbia, Missouri, USA, ${ }^{4}$ Department of Medical Pharmacology and Physiology, University of Missouri, Columbia, Missouri, USA and ${ }^{5}$ School of Chiropractic and Sports Science, Murdoch University, Perth, Western Australia, Australia

(Correspondence should be addressed to J A Kanaley; Email: kanaleyj@missouri.edu)

\begin{abstract}
Objective: The purpose of this study was to compare postprandial satiety regulating hormone responses (pancreatic polypeptide (PP) and peptide tyrosine tyrosine (PYY)) and visual analog scale- (VAS) assessed perceived appetite and satiety between liquid high-protein (HP) and high-carbohydrate (HC) meals in obese women during acute (24-h) caloric restriction.

Design: Eleven obese premenopausal women completed two conditions in random order in which they consumed 1500 calories as six 250-calorie HP meals or six 250-calorie HC meals over a 12-h period. Blood samples were taken at baseline and every 20 min thereafter and analyzed for PP and PYY concentrations. At these same points, perceived hunger and fullness were assessed with a VAS. The incremental area under the curve (iAUC) was used to compare postprandial responses.

Results: The 12-h PP and PYY iAUC were greater $(P \leq 0.05)$ during the HP condition (PP: $4727 \pm 1306 \mathrm{pg} / \mathrm{ml} \times 12 \mathrm{~h}, \mathrm{PYY}: 1373 \pm 357 \mathrm{pg} / \mathrm{ml} \times 12 \mathrm{~h})$ compared with the HC condition (PP: $2300 \pm 528 \mathrm{pg} / \mathrm{ml} \times 12 \mathrm{~h}, \mathrm{PYY}: 754 \pm 246 \mathrm{pg} / \mathrm{ml} \times 12 \mathrm{~h})$. Perceived hunger and fullness were not different between conditions $(P>0.05)$. The greatest changes in PYY and perceived fullness occurred after the morning meals during both conditions.

Conclusions: These data suggest that in obese women during acute caloric restriction before weight loss, i) liquid HP meals, compared with HC meals, result in greater postprandial PP and PYY concentrations, an effect not associated with differential appetite or satiety responses, and ii) mealinduced changes in PYY and satiety are greatest during the morning period, regardless of dietary macronutrient composition.
\end{abstract}

European Journal of Endocrinology 168 593-600

\section{Introduction}

Pancreatic polypeptide (PP) and peptide tyrosine tyrosine (PYY) belong to the gastrointestinal PP-fold family of proteins (1), and experimental studies demonstrate that both peptides are acute satiety signals $(2,3,4)$. PP is secreted from the pancreatic islet $\mathrm{F}$ cells via a vagal cholinergic mechanism in response to a meal (5). I.v. infusions of PP in healthy individuals (4), individuals with Prader-Willi syndrome (6), and mice (7) cause a reduction in food intake and the peptide effects are mediated through $\mathrm{Y}_{4}$ receptor signaling (8). On the other hand, PYY is secreted from the L cells of the intestine in response to a meal (9) and circulates as either $\mathrm{PYY}_{1-36}$ or $\mathrm{PYY}_{3-36}$ (10). $\mathrm{PYY}_{3-36}$ is the truncated form and is the main circulating form of the peptide (10). Exogenous administration of PYY reduces food intake in humans $(2,11)$, rats (11), and mice (11) while $\mathrm{PYY}_{3-36}$ effects are mediated through $\mathrm{Y}_{2}$ receptor signaling $(8,11)$. Collectively, these observations suggest that postprandial PP and PYY secretion constitute an important mechanism in the control of appetite and satiety and that modulation of these hormones might aid in the treatment or prevention of obesity.

Caloric restriction is often the first-line therapy to help treat obesity. Lower calorie diets induce weight loss, but increased hunger and reduced satiety can reduce the compliance of a low-calorie diet. However, altering the composition of the diet may be helpful. Although limited, some studies suggest that chronic higher protein (HP) 
low-calorie diets (protein content $25-34 \%$ of energy) containing conventional solid foods increase perceived satiety more than lower protein, higher carbohydrate (HC) diets (protein content 14-18\% energy) during weight loss in overweight and obese individuals $(12,13$, 14). The increased satiety associated with HP meals during caloric restriction and weight loss may be because protein causes the greatest stimulation of postprandial PP (15) and PYY (16) secretion.

Although studies have compared appetite and satiety responses between $\mathrm{HP}$ and $\mathrm{HC}$ diets composed of conventional solid foods during progressive caloric restriction and weight loss, extrapolation of these findings to liquid foods during acute or chronic caloric restriction is difficult as some studies demonstrate that liquid meals result in lower satiation compared with solid foods $(17,18)$, a response that is not uniform as other studies show no difference in appetite or satiety between liquid and solid foods $(19,20,21)$. Furthermore, results from studies examining differences in appetite and satiety between liquid $\mathrm{HP}$ and $\mathrm{HC}$ meals are mixed. Using liquid preloads, studies demonstrate increased satiety with a liquid HP preload compared with a liquid HC preload $(22,23,24,25,26,27)$, yet other studies show no difference in satiety responses (28). No study has examined postprandial PP, PYY, perceived hunger, and perceived fullness between multiple liquid HP and HC meals over the course of a day in obese women consuming a liquid diet during an acute or chronic period of caloric restriction. In clinical settings, obese individuals are sometimes prescribed a hypocaloric liquid diet to induce weight loss. Therefore, knowledge of how the macronutrient composition of a liquid diet affects postprandial perceived appetite and satiety over the course of an entire day of eating will provide important clinical information about the satiating potential of the liquid diet and potentially dietary compliance and success. Therefore, the primary purpose of this study was to compare postprandial PP, PYY, perceived hunger, and fullness responses between liquid $\mathrm{HP}$ and $\mathrm{HC}$ meals during acute caloric restriction in obese women over the course of $12 \mathrm{~h}$ of feeding. In addition, during caloric restriction, there is evidence that protein consumed at breakfast leads to greater feelings of fullness compared with other times of the day (29), but the hormonal mechanisms are unknown. Therefore, a secondary purpose of this study was to determine whether the time of day alters PP, PYY, and perceived appetite and satiety responses. It was hypothesized that: i) liquid HP meals would produce greater postprandial PP and PYY responses and this would be associated with greater reductions in perceived hunger and increases in fullness compared with the isocaloric $\mathrm{HC}$ meals; and ii) greater feelings of fullness would occur after the breakfast meal, and this would be associated with greater PP and PYY responses.

\section{Materials and methods}

\section{Study population}

The University of Missouri Institutional Review Board reviewed this study and found it ethical to conduct. All participants provided written informed consent before participating. Obese premenopausal women were recruited for this study using email list serves, fliers posted around the community, and word of mouth. Inclusion criteria included a BMI $\geq 30 \mathrm{~kg} / \mathrm{m}^{2}$; body fat percent $>30 \%$ (assessed via the BOD POD), between 30 and 50 years of age; sedentary (engaged in exercise $<1$ time per week); no previous history of sleep apnea; heart, lung, kidney, endocrine, or liver disease; normal fasting blood glucose concentrations $(<100 \mathrm{mg} / \mathrm{dl})$, not on hormone replacement therapy or taking any medications known to alter appetite or satiety; nontobacco users; and not pregnant or lactating.

\section{Study design}

In a crossover design, the participants completed two conditions in random order in which they consumed 1500 liquid calories as six 250-calorie HC meals or six 250-calorie HP meals over a 12 -h period during $24 \mathrm{~h}$ of acute caloric restriction (12-h fast followed by $12 \mathrm{~h}$ of feeding every $2 \mathrm{~h}$ ). The participants were given 1500 calories because a 1200-1500 calorie energy-restricted diet has been shown to be effective for weight loss in obese individuals $(30,31)$. The meals were administered once every $2 \mathrm{~h}$ during the 12-h testing period, and this higher meal frequency was chosen because it has been reported that women in Western cultures consume frequent meals per day, with an average eating occasion of five per day (32). In addition, the women in our study reported consuming between three and six meals per day, and this varied from day to day. Each experimental condition was separated by at least 1 month, occurred during the follicular phase of the menstrual cycle, and the participants were instructed to maintain their normal dietary and physical activity habits while participating in this study. Each participant consumed an energy-balanced diet and kept a dietary record during the 3 days before each 12 -h testing day.

\section{Testing day}

All participants arrived at the laboratory at $0700 \mathrm{~h}$ following a 12-h overnight fast. Upon arrival, a registered nurse inserted a venous catheter into the antecubital vein of the forearm of the participant, which was kept patent with a saline drip. During each condition, venous blood samples were taken at baseline and every $20 \mathrm{~min}$ thereafter for $12 \mathrm{~h}$. The participant's perceived hunger and fullness were assessed with a $100 \mathrm{~mm}$ linear visual analog scale (VAS) at baseline and every $20 \mathrm{~min}$ thereafter. The participants marked 
a single vertical line through the horizontal line of each scale between the extremes (i.e. 'not at all hungry' to 'as hungry as I have ever felt' and 'not at all full' to 'as full as I have ever felt') to indicate their perceived hunger and satiety at that time. The VAS is a valid and reliable scale used to assess appetite and satiety $(33,34)$. During testing, the participants were sedentary and were either sitting or lying down in a bed. The only physical activity they performed was getting up to use the bathroom.

During the HC condition, the meal was a canned Nutritional Drink (Walgreens Co., Deerfield, IL, USA) containing 250 calories ( $8 \mathrm{fl} \mathrm{oz}$ ) as $9 \mathrm{~g}$ protein, $40 \mathrm{~g}$ carbohydrate, $6 \mathrm{~g}$ fat, and $0 \mathrm{~g}$ fiber (energy consisting of $14.4 \%$ protein, $64 \%$ carbohydrate, and $21.6 \%$ fat). The glycemic index of the HC meal was 115 (determined by Nutrition Data System for Research (NDSR), University of Minnesota, Minneapolis, MN, USA). During the HP condition, the meal was made by mixing one half of a can of the Nutritional Drink with $24.5 \mathrm{~g}$ of a commercially available protein supplement (Pro Complex, Optimum Nutrition, Inc., Sunrise, FL, USA), 3 g olive oil (Great Value, Walmart Co., Bentonville, AR, USA), and $4 \mathrm{fl} \mathrm{oz}$ of water so that the drink contained 250 calories ( $8 \mathrm{fl} \mathrm{oz}$ ) as $29 \mathrm{~g}$ protein, $20 \mathrm{~g}$ carbohydrate, $6 \mathrm{~g}$ fat, and $0 \mathrm{~g}$ fiber (energy consisting of $46.4 \%$ protein, $32 \%$ carbohydrate, and $21.6 \%$ fat). The glycemic index was 114 for the HP meal. The energy density was identical between the HP and HC meals and was $4.54 \mathrm{cal} / \mathrm{g}$. The shakes were provided to the participants either as a chocolate or vanilla flavor, depending on the participant's preference.

\section{Body composition}

The BOD POD (Life Measurements, Inc.) was used to assess the body composition of the participants during the screening to determine whether the participants met the inclusion criteria. The participants fasted for $3 \mathrm{~h}$ before being tested and wore skintight clothing during the test. Lung volume was measured and body fat $\%$ was predicted by the computer program using the Siri equation.

\section{Energy balance}

The Mifflin resting energy expenditure (REE) prediction equation (35) was used to calculate the 24-h REE of all the participants as this equation has been shown to be most accurate in obese individuals (36). The participants performed little physical activity during the testing day, thus the REE calculated was multiplied by an activity factor of 1.2 to get the predicted 24-h energy expenditure during the testing day. The average predicted 24-h REE was $1975 \pm 50$ calories, thus the participants were calorically restricted by $475 \pm 50$ calories (calculated as REE - 1500 calories consumed).

\section{Dietary assessment}

To control for the effect that diet could have on PP, PYY, or perceived appetite and satiety responses, the participants kept detailed dietary records during the 3 days before each condition. A photocopy of this dietary record was given to the participants and they were asked to precisely replicate the dietary records before the subsequent visit. Dietary records were analyzed for total energy, macro/micronutrient content, and glycemic index using the NDSR.

\section{Blood handling and analysis}

Venous blood samples $(\sim 3 \mathrm{ml})$ were collected by syringes, transferred immediately into serum separator tubes, and separated by centrifugation at $1409 \boldsymbol{g}$ for $15 \mathrm{~min}$ at $4{ }^{\circ} \mathrm{C}$. The serum was stored in cryogenic vials at $-80{ }^{\circ} \mathrm{C}$ until analysis. The hormone concentrations of PP and PYY (total) were determined from the same sample in duplicate using a MILLIPLEX magnetic beadbased quantitative immunoassay with the MAGPIX instrumentation (Millipore, Billerica, MA, USA). The intra-assay coefficients of variability (CV) among the samples was $10 \%$ for PP and 9\% for PYY while the interassay CV was $11 \%$ for PP and $14 \%$ for PYY.

\section{Statistical analysis}

The Statistical Package for the Social Sciences statistical software, version 18.0 (IBM SPSS Statistics), was used to perform the statistical tests. For the primary analysis, the 12-h postprandial PP, PYY, hunger, and fullness responses were quantified using the incremental area under the curve (iAUC represents change from baseline), which was calculated using the trapezoidal method (37). A paired samples t-test was used to compare the 12-h iAUC between the HP and HC conditions. For the secondary analysis, the 4-h iAUC was calculated for the morning (time 0700-1100 h), afternoon (1100-1500 h), and evening (1500$1900 \mathrm{~h}$ ) and a repeated measures ANOVA was performed with follow-up Bonferroni-adjusted $t$-tests to identify statistically significant differences between the 4-h iAUC during the different times of day within each condition. Statistical significance was set at $P \leq 0.05$ and values are reported as means \pm s.E.M.

\section{Results}

\section{Participant characteristics and diet}

Eleven obese premenopausal women participated in this study. The baseline characteristics of the women are listed in Table 1. The participants remained weight stable while participating in this study (defined as weight gain/loss $<2 \mathrm{~kg}$ ). There were no differences 
Table 1 Participant characteristics. Values are means \pm s.E.M.

\begin{tabular}{lr}
\hline $\boldsymbol{n}=\mathbf{1 1}$ & \\
\hline Age (years) & $40.4 \pm 2.0$ \\
Height $(\mathrm{m})$ & $1.7 \pm 1.6$ \\
Weight $(\mathrm{kg})$ & $97.2 \pm 3.4$ \\
BMI $\left(\mathrm{kg} / \mathrm{m}^{2}\right)$ & $35.4 \pm 1.2$ \\
Body fat percent & $47.1 \pm 1.7$ \\
Waist circumference (cm) & $103.4 \pm 3.7$ \\
Hip circumference $(\mathrm{cm})$ & $121.5 \pm 3.5$ \\
Fasting blood glucose $(\mathrm{mg} / \mathrm{dl})$ & $81.5 \pm 2.4$ \\
Fasting insulin $(\mu \mathrm{IU} / \mathrm{l})$ & $9.4 \pm 1.4$ \\
QUICKI & $0.35 \pm 0.01$ \\
HOMA-IR & $2.06 \pm 0.22$
\end{tabular}

QUICKI, quantitative insulin sensitivity check index; HOMA-IR, homeostatic model of insulin resistance.

in dietary energy consumed, macronutrient composition, or glycemic index during the 3 days before each condition.

\section{Fasting and postprandial hormonal responses}

Figure 1 shows the PP responses during both conditions. Fasting PP concentrations were not significantly different between conditions (Fig. 1B, $P>0.05)$. The 12-h PP iAUC was significantly greater $(P=0.02)$ during the HP condition compared with the HC condition (Fig. 1C). The 4-h iAUC was not significantly different between the morning, afternoon, and evening within each condition (Fig. 1A, P>0.05).

Figure 2 shows the PYY responses during both conditions. Fasting PYY concentrations were not significantly different between conditions (Fig. 2B, $P>0.05$ ). The 12-h PYY iAUC was significantly greater $(P=0.05)$ during the HP condition compared with the HC condition (Fig. 2C). During the HP condition, the rise in PYY concentrations in response to the meals (4-h iAUC) was significantly greater during the morning compared with the afternoon $(P=0.03)$ but not the evening (Fig. 2A, $P>0.05)$. Similarly, during the HC condition, the rise in PYY concentrations during the morning was significantly greater compared with the afternoon $(P=0.01)$ but not the evening (Fig. 2A, P>0.05).

\section{Fasting and postprandial hunger and fullness responses}

Figure 3 shows the perceived hunger responses during both conditions. Baseline hunger ratings were not significantly different between conditions (Fig. 3B, $P>0.05)$. The 12-h hunger iAUC was not significantly different between conditions (Fig. 3C, $P>0.05$ ). During the HP condition, perceived hunger declined more in response to the meals (4-h hunger iAUC) in the morning compared with the afternoon $(P=0.03)$ but not the evening (Fig. 3A, $P<0.05$ ). There were no significant differences in perceived hunger during the different times of day during the $\mathrm{HC}$ condition (Fig. 3A, P>0.05).

Figure 4 shows the perceived fullness responses during both conditions. Baseline fullness ratings were not significantly different between conditions, but there was a trend for baseline fullness to be greater during the HP condition (Fig. 4B, $P=0.055$ ). The 12-h fullness iAUC was not significantly different between conditions (Fig. 4C, $P>0.05$ ). During the HP condition, perceived fullness increased more in response to the meals during the morning compared with the afternoon and evening (Fig. 4A, $P=0.04$ ). Similarly, during the HC condition, perceived fullness increased more in response to the meals during the morning compared with the afternoon and evening (Fig. 4A, $P<0.01$ ).
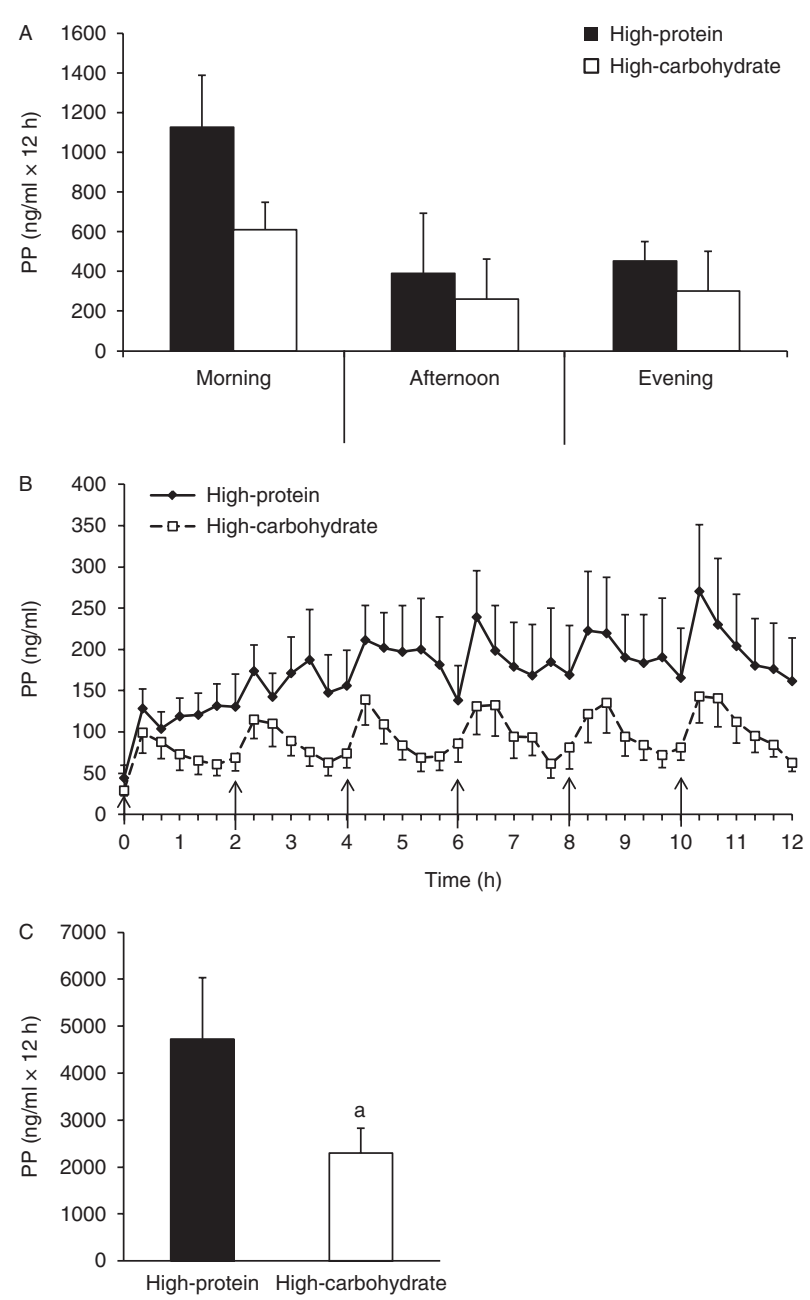

Figure 1 Pancreatic polypeptide $(\mathrm{PP})$ time course and incremental area under the curve (iAUC). (A) The 4-h PP iAUC for the morning, afternoon, and evening periods. (B) Time course of postprandial PP. (C) The 12-h PP iAUC. Values are represented as means \pm S.E.M. $\uparrow$ Meal was eaten. ${ }^{a} P<0.05$ compared with high-protein. 

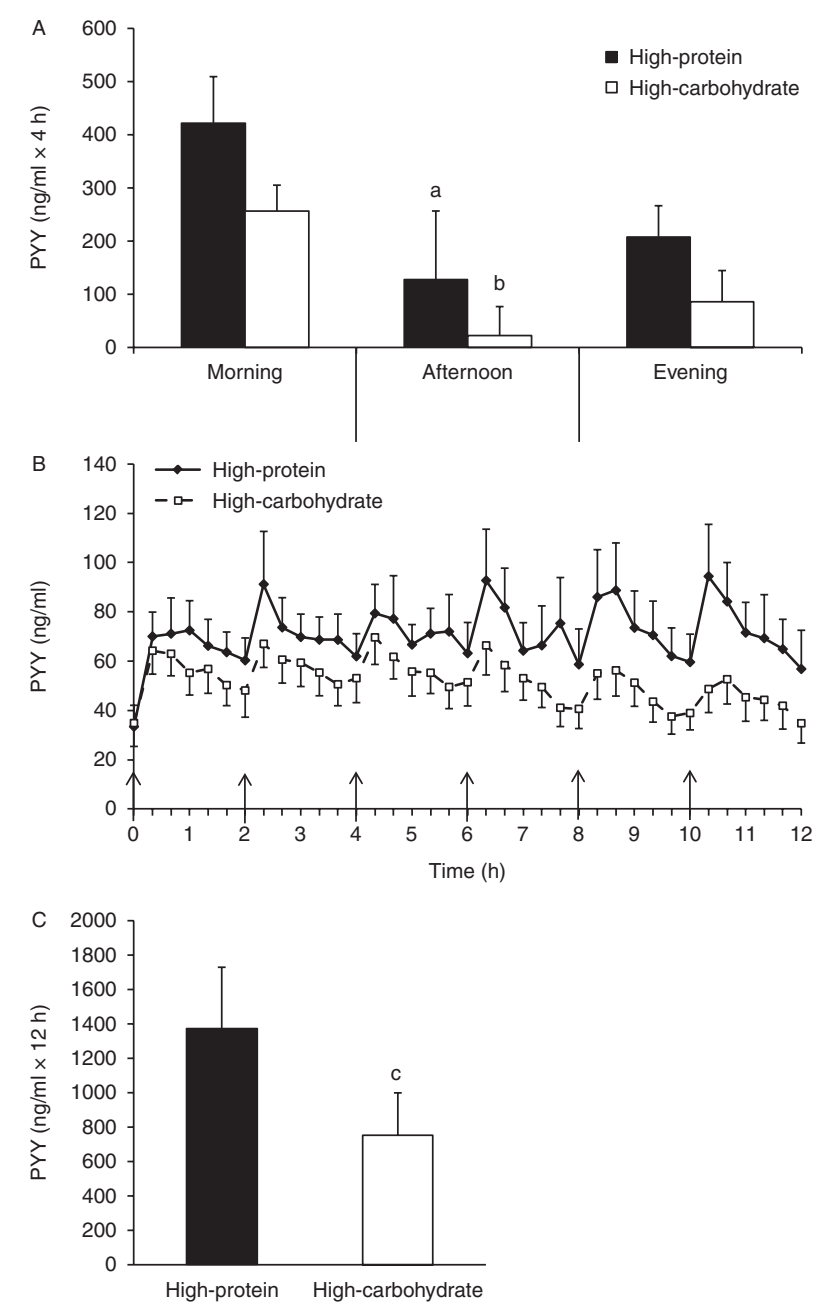

Figure 2 Peptide tyrosine tyrosine (PYY) time course and incremental area under the curve (iAUC). (A) The 4-h PYY iAUC for the morning, afternoon, and evening periods. (B) Time course of postprandial PYY. (C) The 12-h PYY iAUC. Values are represented as means \pm S.E.M. $\uparrow$ Meal was eaten. ${ }^{a} P<0.05$ compared with morning 4-h iAUC within high-protein (HP) condition. ${ }^{\mathrm{b}} P<0.05$ compared with morning 4-h iAUC within high-carbohydrate condition. ${ }^{\mathrm{C}} P<0.05$ compared with HP condition.

\section{Discussion}

The effect of liquid meal composition on the acute satiety signals PP and PYY and perceived appetite and satiety, in obese women during acute caloric restriction, has not been studied. The findings from this study show, for the first time, that during acute caloric restriction liquid HP meals stimulate greater postprandial concentrations of the satiety peptides PP and PYY compared with liquid $\mathrm{HC}$ meals throughout an entire day of eating in obese women, a group that is likely to use a liquid diet to induce weight loss. However, the greater postprandial concentrations of the satiety peptides PP and PYY induced by the liquid HP meals were not associated with greater satiation compared with liquid HC meals. In addition, the greatest increase in PYY and increase in perceived fullness occurred during the morning period during both conditions, and these responses were much less after subsequent meals. These data suggest that in obese women during acute caloric restriction before weight loss, i) liquid HP meals, compared with HC meals, result in greater postprandial PP and PYY concentrations, an effect not associated with altered appetite or satiety, and ii) meal-induced changes in PYY and satiety are greatest during the morning period, regardless of dietary macronutrient composition.

Postprandial PP concentrations remain elevated for up to $6 \mathrm{~h}$ after meal ingestion (38) and the current line of evidence indicates that PP is an acute satiety signal $(4,6,7)$. To our knowledge, only one study has shown that a HP meal induces greater postprandial PP
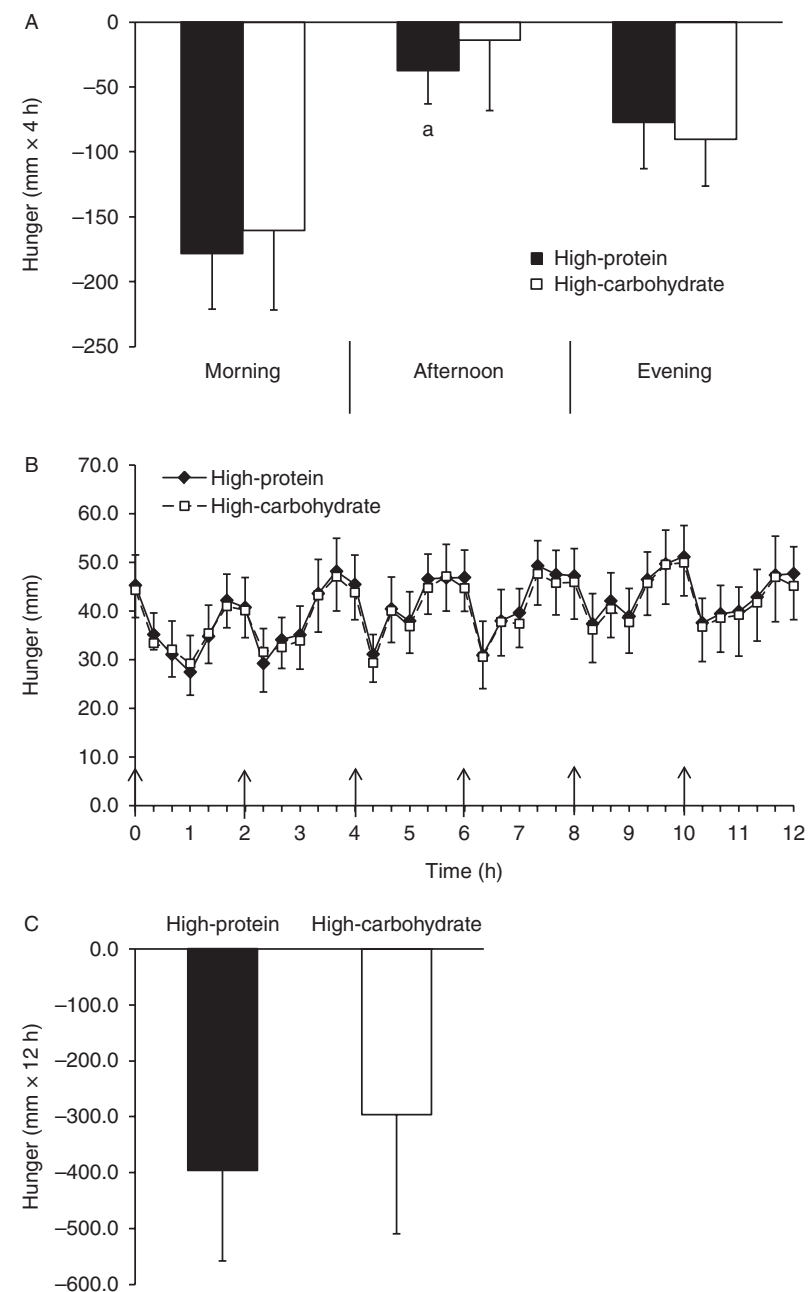

Figure 3 Perceived hunger time course and incremental area under the curve (iAUC). (A) The 4-h hunger iAUC for the morning, afternoon, and evening periods. (B) Time course of postprandial hunger. (C) The 12-h hunger iAUC. Values are represented as means \pm S.E.M. $\uparrow$ Meal was eaten. ${ }^{a} P<0.05$ compared with morning 4-h $i \mathrm{AUC}$ within high-protein condition. 

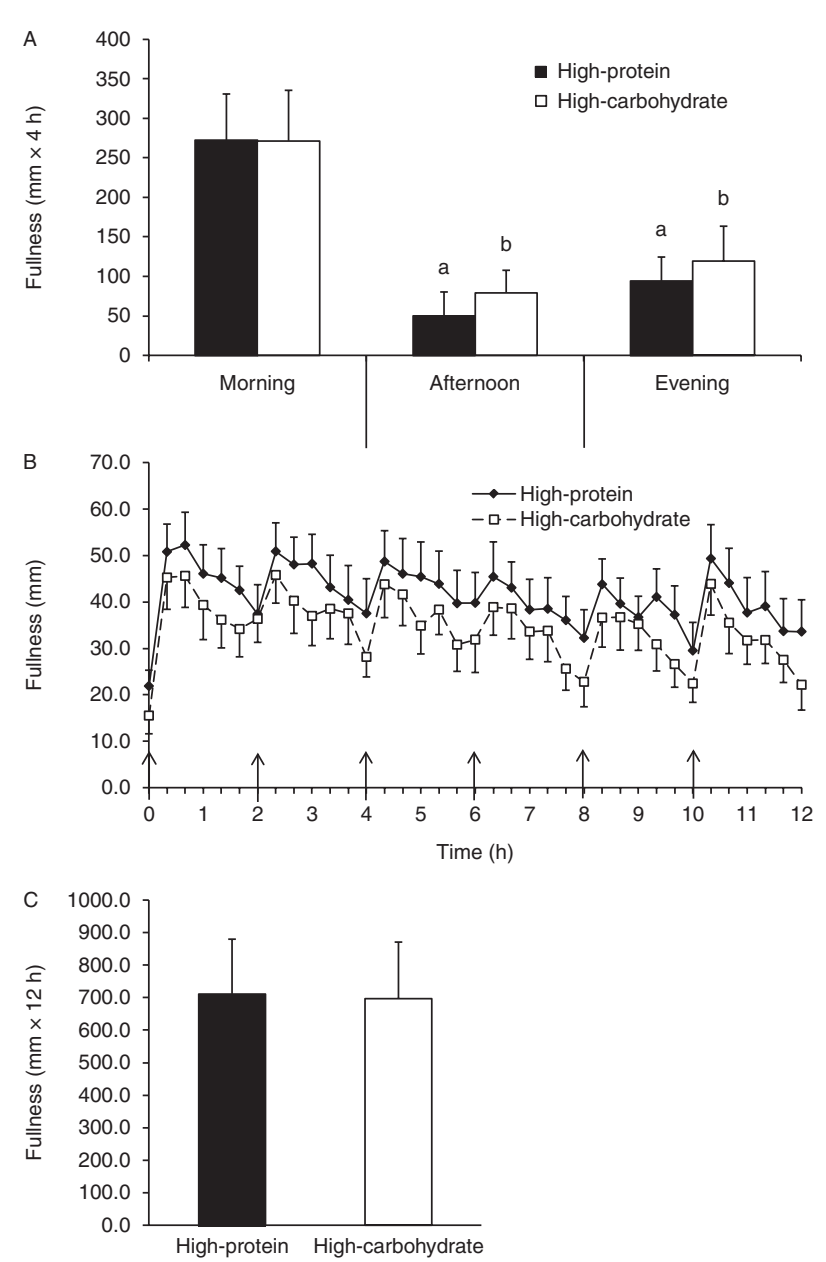

Figure 4 Perceived fullness time course and incremental area under the curve (iAUC). (A) The 4-h fullness iAUC for the morning, afternoon, and evening periods. (B) Time course of postprandial fullness. (C) The 12-h fullness iAUC. Values are represented as means \pm S.E.M. $\uparrow$ Meal was eaten. ${ }^{a} P<0.05$ compared with morning 4-h iAUC within high-protein condition. ${ }^{b} P<0.05$ compared with morning 4-h iAUC within high-carbohydrate condition.

concentrations compared with a lower protein meal (15), and this may be one mechanism by which HP meals induce greater satiation compared with lower protein meals. In line with this study, our data show that liquid HP meals induce greater postprandial PP concentrations compared with liquid HC meals in obese women over the course of $12 \mathrm{~h}$ of eating. The PP response to each meal during both conditions was not significantly different between the different times of day and was highly variable. In addition to $\mathrm{PP}$, the gut hormone $\mathrm{PYY}$ is an acute satiety signal and involved in the regulation of bodyweight $(2,11)$. Our data show greater postprandial PYY concentrations in response to HP meals, compared with $\mathrm{HC}$ meals, and this finding is in agreement with previous work (16). Furthermore, the PYY response to each meal, during both conditions, was greatest in the morning compared with the afternoon and evening.
Despite greater concentrations of the satiety peptides PP and PYY with HP meals in this study, appetite and satiety were not different between liquid HP and HC meals. This response is contrary to most of the published work in this area. The majority of studies that have compared appetite and satiety between liquid $\mathrm{HP}$ and $\mathrm{HC}$ meals have used liquid preloads before ad libitum feeding. Most studies demonstrate that liquid HP preloads decrease energy intake $(22,23,24,25$, $26,27)$ and increase satiety or reduce appetite $(22,25$, $26,27,39)$ more so than liquid HC preloads. This response is not universal as another study demonstrated that liquid HP preloads did not alter satiety or energy intake differently compared with a liquid HC preload (28). In the context of chronic caloric restriction, studies have shown that a HP diet consisting of solid food is associated with greater satiation compared with a lower protein diet $(12,13,14)$. Our data with liquid meals do not support these previous studies and show that during acute caloric restriction, liquid HP meals do not increase perceived fullness or reduce perceived hunger more than liquid HC meals over the course of an entire day of eating. The difference in responses between studies may be because of differences in study designs, test populations, and different test meals. Given the limited research examining the impact of liquid meal macronutrient composition during acute or chronic caloric restriction on appetite and satiety, more research is warranted in obese individuals, a group that is most likely to use a liquid diet for weight loss.

This study has some potential limitations that should be considered when interpreting the findings. First, we examined hormonal and perceived appetite and satiety responses in obese women before weight loss and during an acute (24-h) period of caloric restriction. It is possible that perceived hunger, satiety, and hormonal responses may change over time during or after weight loss when a liquid diet is consumed, although this has not been examined. Previous work that has used solid meals demonstrated that when individuals were fed a HC diet, postprandial perceived fullness declined $\sim 24 \%$ after 12 weeks of caloric restriction compared with baseline, whereas the decline was attenuated with a HP diet (declined 5\%). However, the change in perceived hunger and desire to eat changed minimally ( $<5 \%$ ) from pre- to post-weight loss and was not different between $\mathrm{HP}$ or $\mathrm{HC}$ meals (13). It is possible that the lack of difference between HP and HC meals in the current study may have been that the participants consumed the liquid diet for only one day, but it may be that a longer duration would be required to observe differences in satiety between liquid HP and HC meals. Another limitation of this study is that we did not measure the palatability of the meals. Palatability could have an effect on appetite and satiety ratings (40), which could have influenced the results of our study. In addition to palatability, meal frequency could potentially alter appetite and satiety responses, which could limit the translation of these 
findings to a lower meal frequency (i.e. three meals per day). However, no published study has assessed how liquid meal frequency alters perceived appetite and satiety in obese women during acute caloric restriction. Unpublished observations from our laboratory suggest that liquid meal frequency does not alter perceived appetite or satiety over the course of an entire day of eating in obese men or women during acute caloric restriction. In addition, published observations show that meal frequency (three vs six meals) does not differentially alter perceived appetite or satiety over the course of an entire day of eating solid food in overweight or obese men consuming an energy-balanced diet (41). Lastly, we used Caucasian, obese premenopausal women; thus, extrapolation of these findings to other populations of different sex and age is limited.

In conclusion, these data suggest that liquid HP meals, compared with liquid HC meals, result in greater postprandial PP and PYY concentrations, an effect not associated with altered appetite or satiety, in obese women during an acute period of caloric restriction before weight loss. In addition, meal-induced changes in PYY and satiety are greatest during the morning period compared with the afternoon and evening. The clinical implications of these findings are that a liquid HP diet may not offer any benefit in terms of appetite control compared with a liquid $\mathrm{HC}$ diet in obese individuals beginning a calorically restricted liquid diet. Further, the time of day may influence PYY and perceived satiety responses, thus should be considered when designing studies. Although these findings are a relevant step to identify the acute influences of liquid HP and HC meals on appetite-regulating hormones and perceived appetite and satiety, further research involving other populations and a longer term intervention are required to identify the long-term implications for appetite control, energy regulation, and body composition in all populations.

\section{Declaration of interest}

The authors declare that there is no conflict of interest that could be perceived as prejudicing the impartiality of the research reported.

\section{Funding}

This study was supported by a NIH R21DK084467-01 grant.

\section{Author contribution statement}

T D Heden was involved in data collection and analysis, data interpretation, and manuscript preparation. Y Liu and L Sims were involved in data collection and blood analysis. M L Kearney was involved in data collection and analysis and manuscript preparation. A T Whaley-Connell, A Chockalingam, and K C Dellsperger were involved in data interpretation and manuscript preparation. $\mathrm{T}$ Fairchild was involved in study design, data interpretation, and manuscript preparation. J A Kanaley was involved in study design, data interpretation, data collection and analysis, and manuscript preparation.

\section{Acknowledgements}

The authors would like to thank the nurses of the clinical research unit for helping with catheter insertion and monitoring the subjects. They would also like to thank Dr Heather Leidy for her assistance with the PP and PYY assays.

\section{References}

1 Ekblad E \& Sundler F. Distribution of pancreatic polypeptide and peptide YY. Peptides 200223 251-261. (doi:10.1016/S01969781(01)00601-5)

2 Batterham RL \& Bloom SR. The gut hormone peptide YY regulates appetite. Annals of the New York Academy of Sciences $2003 \mathbf{9 9 4}$ 162-168. (doi:10.1111/j.1749-6632.2003.tb03176.x)

3 Batterham RL, Le Roux CW, Cohen MA, Park AJ, Ellis SM, Patterson M, Frost GS, Ghatei MA \& Bloom SR. Pancreatic polypeptide reduces appetite and food intake in humans. Journal of Clinical Endocrinology and Metabolism 200388 39893992. (doi:10.1210/jc.2003-030630)

4 Jesudason DR, Monteiro MP, McGowan BM, Neary NM, Park AJ, Philippou E, Small CJ, Frost GS, Ghatei MA \& Bloom SR. Low-dose pancreatic polypeptide inhibits food intake in man. British Journal of Nutrition 200797 426-429. (doi:10.1017/S000711 4507336799)

5 Schwartz TW. Pancreatic polypeptide: a unique model for vagal control of endocrine systems. Journal of the Autonomic Nervous System 1983 9 99-111. (doi:10.1016/0165-1838(83)90134-0)

6 Berntson GG, Zipf WB, O’Dorisio TM, Hoffman JA \& Chance RE. Pancreatic polypeptide infusions reduce food intake in PraderWilli syndrome. Peptides 199314 497-503. (doi:10.1016/01969781(93)90138-7)

7 Asakawa A, Inui A, Yuzuriha H, Ueno N, Katsuura G, Fujimiya M, Fujino MA, Niijima A, Meguid MM \& Kasuga M. Characterization of the effects of pancreatic polypeptide in the regulation of energy balance. Gastroenterology 2003124 1325-1336. (doi:10.1016/ S0016-5085(03)00216-6)

8 Hankir MK, Parkinson JR, Minnion JS, Addison ML, Bloom SR \& Bell JD. Peptide YY3-36 and pancreatic polypeptide differentially regulate hypothalamic neuronal activity in mice in vivo as measured by manganese-enhanced magnetic resonance imaging. Journal of Neuroendocrinology 201123 371-380. (doi:10.1111/ j.1365-2826.2011.02111.x)

9 Adrian TE, Ferri GL, Bacarese-Hamilton AJ, Fuessl HS, Polak JM \& Bloom SR. Human distribution and release of a putative new gut hormone, peptide YY. Gastroenterology 198589 1070-1077.

10 Grandt D, Schimiczek M, Beglinger C, Layer P, Goebell H, Eysselein VE \& Reeve JR Jr. Two molecular forms of peptide YY (PYY) are abundant in human blood: characterization of a radioimmunoassay recognizing PYY $1-36$ and PYY 3-36. Regulatory Peptides 199451 151-159. (doi:10.1016/0167-0115 (94)90204-6)

11 Batterham RL, Cowley MA, Small CJ, Herzog H, Cohen MA, Dakin CL, Wren AM, Brynes AE, Low MJ, Ghatei MA et al. Gut hormone PYY(3-36) physiologically inhibits food intake. Nature 2002418 650-654. (doi:10.1038/nature00887)

12 Leidy HJ, Tang M, Armstrong CL, Martin CB \& Campbell WW. The effects of consuming frequent, higher protein meals on appetite and satiety during weight loss in overweight/obese men. Obesity 201119 818-824. (doi:10.1038/oby.2010.203)

13 Leidy HJ, Carnell NS, Mattes RD \& Campbell WW. Higher protein intake preserves lean mass and satiety with weight loss in pre-obese and obese women. Obesity 200715 421-429. (doi:10.1038/oby.2007.531)

14 Moran LJ, Luscombe-Marsh ND, Noakes M, Wittert GA, Keogh JB \& Clifton PM. The satiating effect of dietary protein is unrelated to postprandial ghrelin secretion. Journal of Clinical Endocrinology and Metabolism 200590 5205-5211. (doi:10.1210/jc.2005-0701) 
15 Zipf WB, O'Dorisio TM, Cataland S \& Dixon K. Pancreatic polypeptide responses to protein meal challenges in obese but otherwise normal children and obese children with Prader-Willi syndrome. Journal of Clinical Endocrinology and Metabolism 1983 57 1074-1080. (doi:10.1210/jcem-57-5-1074)

16 Batterham RL, Heffron H, Kapoor S, Chivers JE, Chandarana K, Herzog H, Le Roux CW, Thomas EL, Bell JD \& Withers DJ. Critical role for peptide YY in protein-mediated satiation and body-weight regulation. Cell Metabolism 20064 223-233. (doi:10.1016/j. cmet.2006.08.001)

17 DiMeglio DP \& Mattes RD. Liquid versus solid carbohydrate: effects on food intake and body weight. International Journal of Obesity and Related Metabolic Disorders 200024 794-800. (doi:10.1038/sj. ijo.0801229)

18 Mourao DM, Bressan J, Campbell WW \& Mattes RD. Effects of food form on appetite and energy intake in lean and obese young adults. International Journal of Obesity 200731 1688-1695. (doi:10.1038/sj.ijo.0803667)

19 Kissileff HR. Effects of physical state (liquid-solid) of foods on food intake: procedural and substantive contributions. American Journal of Clinical Nutrition $1985 \mathbf{4 2} 956-965$.

20 Martens MJ, Lemmens SG, Born JM \& Westerterp-Plantenga MS. Satiating capacity and post-prandial relationships between appetite parameters and gut-peptide concentrations with solid and liquefied carbohydrate. PLoS ONE 20127 e42110. (doi:10.1371/journal. pone.0042110)

21 Zijlstra N, Mars M, de Wijk RA, Westerterp-Plantenga MS, Holst JJ \& de Graaf C. Effect of viscosity on appetite and gastro-intestinal hormones. Physiology \& Behavior 200997 68-75. (doi:10.1016/ j.physbeh.2009.02.001)

22 Dove ER, Hodgson JM, Puddey IB, Beilin LJ, Lee YP \& Mori TA. Skim milk compared with a fruit drink acutely reduces appetite and energy intake in overweight men and women. American Journal of Clinical Nutrition 200990 70-75. (doi:10.3945/ajcn. 2008.27411)

23 Bellissimo N, Desantadina MV, Pencharz PB, Berall GB, Thomas SG \& Anderson GH. A comparison of short-term appetite and energy intakes in normal weight and obese boys following glucose and whey-protein drinks. International Journal of Obesity 200832362 371. (doi:10.1038/sj.ijo.0803709)

24 Bertenshaw EJ, Lluch A \& Yeomans MR. Satiating effects of protein but not carbohydrate consumed in a between-meal beverage context. Physiology \& Behavior 200893 427-436. (doi:10.1016/ j.physbeh.2007.09.014)

25 Poppitt SD, McCormack D \& Buffenstein R. Short-term effects of macronutrient preloads on appetite and energy intake in lean women. Physiology \& Behavior 199864 279-285. (doi:10.1016/ S0031-9384(98)00061-4)

26 Bowen J, Noakes M, Trenerry C \& Clifton PM. Energy intake, ghrelin, and cholecystokinin after different carbohydrate and protein preloads in overweight men. Journal of Clinical Endocrinology and Metabolism 200691 1477-1483. (doi:10.1210/jc.20051856)

27 Latner JD \& Schwartz M. The effects of a high-carbohydrate, high-protein or balanced lunch upon later food intake and hunger ratings. Appetite 199933 119-128. (doi:10.1006/appe. 1999.0237)

28 Soenen S \& Westerterp-Plantenga MS. No differences in satiety or energy intake after high-fructose corn syrup, sucrose, or milk preloads. American Journal of Clinical Nutrition $2007 \mathbf{8 6}$ 1586-1594.

29 Leidy HJ, Bossingham MJ, Mattes RD \& Campbell WW. Increased dietary protein consumed at breakfast leads to an initial and sustained feeling of fullness during energy restriction compared to other meal times. British Journal of Nutrition 2009101 798-803. (doi:10.1017/S0007114508051532)

30 Ditschuneit HH, Flechtner-Mors M, Johnson TD \& Adler G. Metabolic and weight-loss effects of a long-term dietary intervention in obese patients. American Journal of Clinical Nutrition 1999 69 198-204.

31 Wadden TA, Foster GD, Sarwer DB, Anderson DA, Gladis M, Sanderson RS, Letchak RV, Berkowitz RI \& Phelan S. Dieting and the development of eating disorders in obese women: results of a randomized controlled trial. American Journal of Clinical Nutrition 200480 560-568.

32 Kant AK \& Graubard BI. Secular trends in patterns of self-reported food consumption of adult Americans: NHANES 1971-1975 to NHANES 1999-2002. American Journal of Clinical Nutrition 2006 84 1215-1223.

33 Flint A, Raben A, Blundell JE \& Astrup A. Reproducibility, power and validity of visual analogue scales in assessment of appetite sensations in single test meal studies. International Journal of Obesity and Related Metabolic Disorders 200024 38-48. (doi:10.1038/sj. ijo.0801083)

34 Parker BA, Sturm K, MacIntosh CG, Feinle C, Horowitz M \& Chapman IM. Relation between food intake and visual analogue scale ratings of appetite and other sensations in healthy older and young subjects. European Journal of Clinical Nutrition $2004 \mathbf{5 8}$ 212-218. (doi:10.1038/sj.ejcn.1601768)

35 Mifflin MD, St Jeor ST, Hill LA, Scott BJ, Daugherty SA \& Koh YO. A new predictive equation for resting energy expenditure in healthy individuals. American Journal of Clinical Nutrition 199051 241-247.

36 Frankenfield DC, Rowe WA, Smith JS \& Cooney RN. Validation of several established equations for resting metabolic rate in obese and nonobese people. Journal of the American Dietetic Association 2003103 1152-1159. (doi:10.1016/S0002-8223 (03)00982-9)

37 Pruessner JC, Kirschbaum C, Meinlschmid G \& Hellhammer DH. Two formulas for computation of the area under the curve represent measures of total hormone concentration versus timedependent change. Psychoneuroendocrinology 200328 916-931. (doi:10.1016/S0306-4530(02)00108-7)

38 Adrian TE, Bloom SR, Bryant MG, Polak JM, Heitz PH \& Barnes AJ. Distribution and release of human pancreatic polypeptide. Gut 197617 940-944. (doi:10.1136/gut.17.12.940)

39 Harper A, James A, Flint A \& Astrup A. Increased satiety after intake of a chocolate milk drink compared with a carbonated beverage, but no difference in subsequent ad libitum lunch intake. British Journal of Nutrition 200797 579-583. (doi:10.1017/ S0007114507339846)

40 Yeomans MR, Gray RW, Mitchell CJ \& True S. Independent effects of palatability and within-meal pauses on intake and appetite ratings in human volunteers. Appetite 199729 61-76. (doi:10.1006/appe.1997.0092)

41 Leidy HJ, Armstrong CL, Tang M, Mattes RD \& Campbell WW. The influence of higher protein intake and greater eating frequency on appetite control in overweight and obese men. Obesity $2010 \mathbf{1 8}$ 1725-1732. (doi:10.1038/oby.2010.45)

Received 8 October 2012

Revised version received 16 December 2012

Accepted 31 January 2013 